\title{
THE USE OF DATA SET OF THE HUNGARIAN CASE-CONTROL SURVEILLANCE OF CONGENITAL ABNORMALITIES FOR EVALUATION OF BIRTH OUTCOMES BEYOND BIRTH DEFECTS
}

\author{
Andrew E. Czeizel, Erzsébet H. Puhó, Zoltán Kazy \\ Foundation for the Community Control of Hereditary Diseases, Budapest, Hungary
}

\section{SUMMARY}

Aims: To use the data set of the Hungarian Case-Control Surveillance of Congenital Abnormalities (HCCSCA) for the evaluation of birth outcomes beyond congenital abnormalities and to show as example the study of 49 antimicrobial drugs used in Hungary for the reduction of preterm births.

Methods: The population-based data set of the Hungarian Case-Control Surveillance of Congenital Abnormalities, 1980-1996, included 38,151 newborn infants without birth defects and this sample represented 1.8\% of Hungarian births. Medically recorded gestational age at delivery and birthweight, in addition the rate of preterm births and low birthweight newborns born to mothers with or without different antimicrobial drugs used at least by ten pregnant women were analysed.

Results: Of 49 antimicrobial drugs, two: ampicillin (adjusted POR with 95\% Cl: $0.8,0.7-0.9)$ and clotrimazole $(0.8,0.7-0.9)$ showed a preterm birth preventive effect. This preterm preventive effect was found mainly after the use of ampicillin and clotrimazole during the first trimester of pregnancy.

Conclusions: Ampicillin and clotrimazole may be effective for the reduction of preterm births due to infectious diseases of pregnant women in general but particularly caused by genital infections. However, the limitation of the data set did not allow the appropriate evaluation of some antimicrobial drugs (e.g. clindamycin).

Key words: antimicrobial drugs, preterm birth, low birthweight, population-based study

Address for correspondence: A. E. Czeizel, 1026 Budapest, Törökvész lejtő 32, Hungary. E-mail: czeizel@interware.hu

\section{INTRODUCTION}

Current experimental animal investigations do not allow the direct extrapolation of results to human population due to species differences. Thus the harsh reality is that humans are the ultimate test model for detection of adverse drug reactions including teratogenic and fetotoxic effect. However, clinical trials conducted before approval and marketing of a drug generally cannot include pregnant women. Thus the most important objective of the Hungarian Case-Control Surveillance of Congenital Abnormalities (HCCSCA) has been the postmarketing surveillance of drug teratogenicity (1). However, we cannot evaluate the drug teratogenicity without the knowledge and analysis of maternal characteristics, pregnancy complications, maternal diseases and births outcomes, e.g. preterm birth.

The rate of preterm births is very high (about 9\%) in Hungary, therefore preterm birth is the most common cause of infant mortality and morbidity (2). Several causes of preterm births are known but genital tract infections are believed to account for $40 \%$ of spontaneous preterm births $(3,4)$.
The aim of this paper is to show how we can use the data of the HCCSCA for the evaluation for the possible causes of preterm births and to summarise our findings regarding the possible preventive effect of preterm birth related genital organs' infections/diseases of antimicrobial drugs used during pregnancy.

\section{MATERIAL AND METHODS}

The mission and description of the HCCSCA were published previously (1). Only controls of the HCCSCA are evaluated here because congenital abnormalities may have a more drastic effect on preterm birth than drugs studied.

Controls were defined as newborn infants without congenital abnormalities in the HCCSCA and they were selected from the National Birth Registry of the Central Statistical Office for the HCCSCA. In general two controls were matched with every case with congenital abnormalities according to sex, week of birth in the year when the infant was born, and district of parents' residence. Only one newborn from multiple pregnancies was se- 
lected randomly for this analysis. Cases affected with congenital abnormalities for the HCCSCA were recorded in the Hungarian Congenital Abnormality Registry (5).

Gestational age was calculated from the first day of the last menstrual period. The definition of preterm births was a birth before the 37th completed gestational week (less than 259 days). In addition we evaluated the rate of low birthweight newborns (birth weight less than 2,500 g).

We took part in an international collaborative study supported by the European Union BIOMED programme, and evaluated the possible teratogenic effect of all (82) antimicrobial drugs in the HCCSCA(6). However, we decided to test the hypothesis whether antimicrobial treatments prevent preterm birth and/or low birthweight (intrauterine growth retardation) due to the eradication of abnormal vaginal flora or infections/diseases of female genital organs. Here, the data of 49 antimicrobial drugs used at least by 10 pregnant women are summarised in the population-based data set of the HCCSCA (1).

Exposure and confounder data were obtained from three sources.

(1) Prospective medically recorded data. An explanatory letter was mailed to the mothers immediately after the selection of newborns from the National Birth Registry for the HCCSCA explaining the objective of the study and asking them to send us the prenatal care logbook (containing medicines prescribed by obstetricians), the discharge summary of delivery (including birth weight and gestational age), and all other medical records concerning the study pregnancy. Prenatal care was mandatory for pregnant women in Hungary (if pregnant woman did not visit prenatal care, she was not entitled to obtain maternity grant and leave), thus nearly $100 \%$ of pregnant women visited prenatal care, first between the 6th and 12th week of gestation with an average of 7 visits during their pregnancies. Practically all deliveries took place in inpatient obstetric clinics and birth attendants were obstetricians.

(2) Retrospective maternal self-reported information. A structured questionnaire with lists of medicinal products (drugs and pregnancy supplements) and diseases were also sent to the mothers and the printed form of informed consent. The questionnaire requested information on parental demographic data, history of previous pregnancies, medicine intakes, pregnancy complications and maternal diseases during the study pregnancy according to gestational months. To standardize the answers, mothers were asked to read the enclosed lists of medicines and diseases as a memory aid before they replied.

The average time between the end of pregnancy and return of "information package” (including prenatal logbook, questionnaire, etc.) by our prepaid envelope was $5.2 \pm 2.0$ months in $82.6 \%$ of mothers.

(3) Supplementary data collection in non-respondent mothers. Two hundred non-respondent mothers $(0.4 \%)$ were visited at home by regional nurses as part of a validation study (7). Regional nurses helped mothers to fill-in the same questionnaire completed by the evaluation of available medical records.

Thus finally the necessary data were available in $83.0 \%$ of mothers. We can use the data of prenatal care logbooks in 93.8\% of evaluated mothers. Here the data set of the HCCSCA, 1980-1996, is shown because the data collection was changed after 1996.
The evaluation of antimicrobial drug treatments was based on nine approaches: (a) Three sources of information were differentiated: (i) prospective data from medical records only; (ii) retrospective self-reported maternal information from the questionnaire only; and (iii) concordant data from both medical records and questionnaire. (b) Type of treatment: drug studied alone or with other drugs. (c) The route of administration: oral, vaginal, topical, parenteral. (d-e) The dose and duration of treatment. (f) The onset of treatment was evaluated according to gestational months. (g) The reason for treatment, e.g. bacterial vaginosis and (h) pregnancy complications which were medically recorded in prenatal logbook. (i) Confounding factors such as maternal age, birth order, maternal marital and employment status as indicator of socioeconomic status, maternal disorders, drug intakes and pregnancy supplements.

Statistical analyses were performed using the software package SAS version 8.02 (SAS Institute Ins., Cary, North Caroline, USA). First, mean gestational age and birth weight of controls born to mothers with different antimicrobial drug treatments were compared with the mean gestational age and birth weight of newborn infants born to mothers without this treatment and adjusted Student t-test was calculated. At the analyses of the preterm birth and low birthweight rates we used unconditional logistic regression model to compare the treated group with the untreated group, and adjusted prevalence odds ratios (POR) with 95\% confidence interval (95\% CI) were evaluated. At the calculation of adjusted POR in each antimicrobial drug studied, birth order, maternal age, employment status and other antimicrobial drugs were used as confounders. Finally, we analysed separately the drugs with a potential preventive effect to preterm birth according to the treatment in different trimesters of pregnancy.

\section{RESULTS}

During the study period 2,146,574 total births were recorded in Hungary, thus 38,151 newborn infants in our study sample represented $1.8 \%$ of all Hungarian births recorded between 1980 and 1996. The mean (S.D.) gestational age at delivery and birth weight were $39.4 \pm 2.0$ weeks and $3.276 \pm 511$ gram while the proportion of preterm birth and low birthweight was $9.2 \%$ and $5.7 \%$ during the study period in our sample, respectively. These figures and the distribution of gestational age (weeks) and birth weight (500 g) groups were consistant with the data of the Hungarian newborn population.

Mean maternal age was $25.3 \pm 4.9$ years with the mean birth order $1.7 \pm 0.9$ in the Hungarian pregnant population during the study period while these figures were between $24.5 \pm 4.0$ and 26.2 \pm 4.8 years, and $1.6 \pm 0.9$ and $1.9 \pm 1.1$ in pregnant women with different antimicrobial drug treatments. Among Hungarian pregnant women the proportion of high employment (professional and managerial) and low employment (semi- and unskilled workers) status was $32.8 \%$ and $38.4 \%$, respectively. Pregnant women with antimicrobial drug treatment had a somewhat larger proportion of high employment status (38.0\%) in the HCCSCA.

Of 38,151 controls, 16,654 (43.7\%) mothers suffered from an acute maternal infectious disease (some pregnant women had more than one disease) as the main indication for various antimicrobial drug treatments during pregnancy under study 
(Table 1). Most diseases were medically recorded and these pathological conditions were classified as urogenital and nonurogenital infectious diseases. If pregnant women had both urogenital and non-urogenital disease, they were classified in the group of urogenital diseases. However, if pregnant women had acute infectious disease of both genital organ and urinary tract, they were classified as genital organ's diseases.

Mainly antifungal (e.g. clotrimazole) and antiparasitic (mainly metronidazole) drugs were used for the treatment of infectious diseases of the genital organs. The proportion of medically recorded antimicrobial drug treatments showed a wide spectrum depending on their potential teratogenic effect (e.g. nearly all doxycycline treatments were medically recorded because these drugs are on the list of human teratogenic drugs as tetracycline, while only a low proportion of penicillins were medically recorded because these drugs are not considered as human teratogens), and on the medical doctors who prescribed these drugs (e.g. in general metronidazole was prescribed by obstetricians in prenatal care and recorded in prenatal logbook, while benzylpenicillin prescribed by general practitioners was not recorded in prenatal logbook). However, there was no difference in the proportion of medically recorded drug treatments between the groups of term and preterm births.

There was no significant difference in the prevalence of the usual pregnancy complications such as nausea-vomiting and preeclampsia in mothers with or without antimicrobial drug treatments.

Table 2 summarizes data of 14 antimicrobial drug groups including 49 drugs which were used at least by 10 pregnant women.
When evaluating the mean of gestational age at delivery, two drugs: phenoxymethylpenicillin and nitrofurantoin were associated with a significantly shorter mean gestational age compared to the reference value (total control group). These two drugs were associated with a higher rate of preterm birth as well. However, there was a significantly longer mean gestational age at delivery and lower rate of preterm birth after the treatment of ampicillin and clotrimazole.

A significant reduction of preterm births was also found due to econazole treatment, but this association was based on only three preterm babies, therefore econazole was not considered after all. On the other hand there was a somewhat higher rate of preterm births after oxacillin, sulfamethoxazole+trimethoprin and metronidazole treatment during pregnancy.

A significant increase of the mean birth weight was found after the use of penamecillin ( $56 \mathrm{~g}$ ), spiramycin ( $227 \mathrm{~g}$ ), isoniazid (227 g), morodyxine (256 g) and cefaclor (269 g) during pregnancy, however, cefalexin (30 g) was associated with a lower mean birth weight.

The proportion of low birthweight newborns was somewhat larger in the group of cefalexin and furazidine.

The so-called preterm birth preventive effect of ampicillin and clotrimazole was evaluated according to the trimesters of treatment (Table 3). The preterm birth preventive effect of ampicillin was seen only after the treatment in the first trimester of gestation. This beneficial effect of clotrimazole was found after its use during both the first and second trimester, though it was most obvious in the early pregnancy.

Table 1. Distribution and number of acute maternal infectious diseases according to the group of antimicrobial drugs

\begin{tabular}{|c|c|c|c|c|c|c|c|c|c|}
\hline \multirow{3}{*}{$\begin{array}{l}\text { Antimicrobial } \\
\text { drug groups }\end{array}$} & \multirow{3}{*}{$\begin{array}{c}\text { Total } \\
\text { No. }\end{array}$} & \multicolumn{4}{|c|}{ Urogenital } & \multicolumn{4}{|c|}{ Non-urogenital } \\
\hline & & \multicolumn{4}{|c|}{$\begin{array}{c}\text { Genital Urinary tract } \\
\text { without other acute } \\
\text { maternal infectious diseases }\end{array}$} & \multicolumn{2}{|c|}{$\begin{array}{c}\text { Influenza - } \\
\text { common cold - } \\
\text { Respiratory system }\end{array}$} & \multicolumn{2}{|c|}{ Others } \\
\hline & & No. & $\%$ & No. & $\%$ & No. & $\%$ & No. & $\%$ \\
\hline Total & 38,151 & 2,891 & 7.5 & 2,301 & 6.0 & 9,577 & 25.1 & 1,885 & 4.9 \\
\hline Penicillins & 5,085 & 493 & 9.7 & 927 & 40.3 & 3,530 & 36.9 & 266 & 14.1 \\
\hline Tetracyclines & 289 & 48 & 16.6 & 48 & 2.1 & 189 & 2.0 & 29 & 1.5 \\
\hline Cephalosporines & 431 & 55 & 12.8 & 211 & 9.2 & 205 & 2.1 & 32 & 1.7 \\
\hline Macrolides & 215 & 39 & 18.1 & 21 & 0.9 & 127 & 1.3 & 20 & 1.1 \\
\hline $\begin{array}{l}\text { Clinda/lyncomycin+ } \\
\text { aminoglycosides }\end{array}$ & 56 & 9 & 16.1 & 18 & 0.8 & 22 & 0.2 & 19 & 1.0 \\
\hline Chloramphenicol & 56 & 8 & 14.3 & 19 & 0.8 & 15 & 0.2 & 14 & 0.7 \\
\hline Sulfonamides & 236 & 33 & 14.0 & 94 & 4.1 & 106 & 1.1 & 29 & 1.5 \\
\hline $\begin{array}{l}\text { Sulfonamides + } \\
\text { trimethropim }\end{array}$ & 479 & 66 & 13.8 & 176 & 7.6 & 256 & 2.7 & 39 & 2.1 \\
\hline Isoniazid & 11 & 1 & 9.1 & 2 & 0.1 & 6 & 0.1 & 15 & 0.8 \\
\hline Other antibacterial & 1,630 & 179 & 11.0 & 1,157 & 50.3 & 405 & 4.2 & 201 & 10.7 \\
\hline Antiviral & 28 & 7 & 25.0 & 1 & 0.0 & 16 & 0.2 & 16 & 0.8 \\
\hline Antifungal & 3,421 & 1,861 & 64.9 & 56 & 2.4 & 1,067 & 11.1 & 333 & 17.7 \\
\hline Antiparasitic & 1,434 & 888 & 61.9 & 15 & 0.7 & 409 & 4.3 & 49 & 2.6 \\
\hline
\end{tabular}


Table 2. Mean gestational age at delivery and birth weight, in addition proportion (\%) of preterm births and low birthweight newborn infants born to mothers with different antimicrobial drug treatments during the study pregnancy compared to the baseline figures of the total data set as reference

\begin{tabular}{|c|c|c|c|c|c|c|c|c|c|c|c|c|c|c|c|c|c|}
\hline \multirow{3}{*}{$\begin{array}{l}\text { Antimicrobial drugs } \\
\text { (route of administration) } \\
\text { Total } \\
\end{array}$} & \multirow{3}{*}{\begin{tabular}{|c|} 
No. \\
38,151 \\
\end{tabular}} & \multicolumn{2}{|c|}{$\begin{array}{l}\text { Gestational age } \\
\text { at delivery }\end{array}$} & \multicolumn{2}{|c|}{ Adjusted* } & \multicolumn{2}{|c|}{ Preterm birth } & \multicolumn{2}{|c|}{ Adjusted* } & \multicolumn{2}{|c|}{ Birth weight } & \multicolumn{2}{|c|}{ Adjusted** } & \multicolumn{2}{|c|}{$\begin{array}{l}\text { Low birth- } \\
\text { weight }\end{array}$} & \multicolumn{2}{|c|}{ Adjusted** } \\
\hline & & Mean & S.D. & $\mathrm{t}$ & $\mathbf{P}$ & No. & $\%$ & POR & $95 \% \mathrm{Cl}$ & Mean & S.D. & $\mathrm{t}$ & $\mathbf{P}$ & No. & $\%$ & POR & $95 \% \mathrm{Cl}$ \\
\hline & & 39.36 & 2.0 & \multicolumn{2}{|c|}{ reference } & 3,496 & 9.2 & \multicolumn{2}{|c|}{ reference } & 3276 & 511 & \multicolumn{2}{|c|}{ reference } & 2,167 & 5.7 & \multicolumn{2}{|c|}{ reference } \\
\hline Penicillins & & & & & & & & & & & & & & & & & \\
\hline Benzylpenicillin $(p)$ & 302 & 39.32 & 2.0 & 0.7 & 0.50 & 27 & 8.9 & 1.0 & $0.7-1.5$ & 3284 & 512 & 0.1 & 0.92 & 19 & 6.3 & 1.3 & $0.8-2.2$ \\
\hline Phenoxymethylpenicillin (0) & 220 & 39.03 & 2.3 & 2.8 & 0.005 & 31 & 14.1 & 1.7 & $1.2-2.6$ & 3276 & 506 & -0.8 & 0.43 & 11 & 5.0 & 0.7 & $0.3-1.3$ \\
\hline Penamecillin (0) & 2,246 & 39.46 & 2.0 & -1.7 & 0.08 & 180 & 8.0 & 0.9 & $0.8-1.1$ & 3332 & 486 & -2.3 & 0.02 & 101 & 4.5 & 0.9 & $0.7-1.1$ \\
\hline Ampicillin (0) & 2,630 & 39.52 & 2.0 & -3.3 & 0.001 & 186 & 7.1 & 0.8 & $0.7-0.9$ & 3298 & 518 & 1.6 & 0.12 & 145 & 5.5 & 0.9 & $0.7-1.6$ \\
\hline Amoxicillin (0) & 10 & 39.20 & 1.2 & 0.4 & 0.67 & 0 & 0.0 & - & - & 3449 & 452 & -0.9 & 0.35 & 0 & 0.0 & - & - \\
\hline Amoxicillin+clavulan acid (0) & 56 & 39.25 & 1.8 & 0.6 & 0.56 & 4 & 7.1 & 0.9 & $0.3-2.4$ & 3367 & 441 & -1.7 & 0.09 & 2 & 3.6 & 0.6 & $0.1-2.7$ \\
\hline Oxacillin (0) & 19 & 39.00 & 2.2 & 1.0 & 0.34 & 4 & 21.0 & 3.2 & $1.0-9.5$ & 3285 & 490 & -1.1 & 0.29 & 1 & 5.3 & 0.4 & $0.0-3.6$ \\
\hline Tetracyclines & & & & & & & & & & & & & & & & & \\
\hline Oxytetracycline (0) & 211 & 39.28 & 2.2 & 0.5 & 0.63 & 23 & 10.9 & 1.2 & $0.8-1.8$ & 3339 & 507 & -1.5 & 0.14 & 11 & 5.2 & 0.8 & $0.4-1.7$ \\
\hline Doxycycline (0) & 78 & 39.81 & 2.0 & -1.7 & 0.09 & 3 & 3.8 & 0.4 & $0.1-1.4$ & 3309 & 598 & 1.0 & 0.32 & 5 & 6.4 & 2.0 & $0.8-5.4$ \\
\hline Cephalosporines & & & & & & & & & & & & & & & & & \\
\hline Cefalexin (0) & 373 & 39.41 & 2.1 & -0.0 & 0.98 & 28 & 7.5 & 0.9 & $0.6-1.3$ & 3249 & 514 & 2.1 & 0.04 & 26 & 7.0 & 1.6 & $1.0-2.5$ \\
\hline Cefuroxime (0) & 45 & 39.98 & 1.5 & -1.7 & 0.08 & 1 & 2.2 & 0.3 & $0.0-2.0$ & 3379 & 564 & -0.7 & 0.49 & 0 & 0.0 & - & - \\
\hline Cefaclor (0) & 23 & 39.83 & 1.8 & -1.0 & 0.34 & 1 & 4.3 & 0.5 & $0.1-3.8$ & 3545 & 474 & -2.6 & 0.009 & 0 & 0.0 & - & - \\
\hline Macrolides & & & & & & & & & & & & & & & & & \\
\hline Erythromycin (0) & 172 & 39.49 & 1.8 & -0.5 & 0.64 & 13 & 7.6 & 0.9 & $0.5-1.6$ & 3326 & 492 & -0.4 & 0.68 & 5 & 2.9 & 0.5 & $0.2-1.4$ \\
\hline Oleandomycin (0) & 15 & 39.53 & 1.3 & -0.2 & 0.81 & 1 & 6.7 & 0.8 & $0.1-6.0$ & 3322 & 294 & -0.1 & 0.91 & 0 & 0.0 & - & - \\
\hline Spiramycin (0) & 14 & 39.21 & 2.1 & 0.4 & 0.72 & 2 & 14.3 & 1.9 & $0.4-8.6$ & 3503 & 785 & -2.2 & 0.03 & 1 & 7.1 & 1.1 & $0.1-10.0$ \\
\hline Roxithromycin (0) & 16 & 39.19 & 2.0 & 0.6 & 0.52 & 2 & 12.5 & 1.9 & $0.4-8.2$ & 3383 & 396 & -1.4 & 0.16 & 0 & 0.0 & - & - \\
\hline Clindamycin - lyncomycin (0) & 11 & 39.54 & 1.6 & -0.3 & 0.77 & 1 & 9.1 & 1.1 & $0.1-8.5$ & 3297 & 618 & -0.4 & 0.69 & 0 & 0.0 & - & - \\
\hline Aminoglycosides & & & & & & & & & & & & & & & & & \\
\hline Gentamycin (p) & 31 & 39.16 & 2.2 & 0.5 & 0.61 & 4 & 12.9 & 1.4 & $0.5-4.1$ & 3128 & 534 & 0.7 & 0.46 & 3 & 9.7 & 1.8 & $0.5-6.7$ \\
\hline Neomycin (0) & 14 & 39.07 & 1.6 & 0.7 & 0.50 & 1 & 7.1 & 0.9 & $0.1-6.8$ & 3192 & 444 & 1.0 & 0.31 & 2 & 14.3 & 4.4 & $0.8-25.1$ \\
\hline Chloramphenicol (0) & 56 & 38.91 & 2.1 & 1.5 & 0.13 & 8 & 14.3 & 1.5 & $0.7-3.3$ & 3262 & 464 & -0.5 & 0.64 & 4 & 7.1 & 0.9 & $0.3-2.9$ \\
\hline Sulfonamides & & & & & & & & & & & & & & & & & \\
\hline Sulfamethazine (0) & 21 & 39.57 & 2.1 & -0.5 & 0.63 & 2 & 9.5 & 1.1 & $0.2-4.6$ & 3478 & 403 & -1.9 & 0.06 & 0 & 0.0 & - & - \\
\hline Sulfathiourea (0) & 72 & 38.97 & 2.2 & 1.5 & 0.14 & 10 & 13.9 & 1.5 & $0.8-2.9$ & 3309 & 452 & -1.4 & 0.16 & 2 & 2.8 & 0.3 & $0.1-1.4$ \\
\hline Sulfamethadiazine (0) & 42 & 39.24 & 1.7 & 0.6 & 0.58 & 2 & 4.8 & 0.5 & $0.1-2.2$ & 3317 & 421 & 0.2 & 0.83 & 0 & 0.0 & - & - \\
\hline $\begin{array}{l}\text { Sulfamethazine+sulfathiourea } \\
\text { +sulfamethoxypyridazine (0) }\end{array}$ & 27 & 39.33 & 2.0 & 0.2 & 0.86 & 4 & 14.8 & 1.8 & $0.6-5.4$ & 3346 & 536 & -1.0 & 0.33 & 1 & 3.7 & 0.5 & $0.1-4.4$ \\
\hline Sulfaguanidine (0) & 26 & 38.96 & 2.5 & 1.0 & 0.34 & 4 & 15.4 & 1.8 & $0.6-5.3$ & 3332 & 649 & -1.1 & 0.28 & 1 & 3.9 & 0.4 & $0.0-3.2$ \\
\hline Sulfonamides+trimethropim & & & & & & & & & & & & & & & & & \\
\hline $\begin{array}{l}\text { Sulfamethoxazole+trimethro- } \\
\text { pim (o) }\end{array}$ & 443 & 39.24 & 2.2 & 1.5 & 0.13 & 53 & 12.0 & 1.4 & $1.0-1.9$ & 3251 & 529 & 0.7 & 0.47 & 31 & 7.1 & 1.2 & $0.8-1.8$ \\
\hline $\begin{array}{l}\text { Sulfamethazine+ } \\
\text { trimethropim (0) }\end{array}$ & 39 & 38.87 & 2.1 & 1.6 & 0.10 & 5 & 12.8 & 1.5 & $0.6-4.0$ & 3253 & 555 & -0.1 & 0.96 & 1 & 2.6 & 0.3 & $0.0-2.3$ \\
\hline Antituberculosis drugs & & & & & & & & & & & & & & & & & \\
\hline Isoniazid (0) & 17 & 39.82 & 1.7 & -0.9 & 0.37 & 1 & 5.9 & 0.7 & $0.1-5.0$ & 3503 & 619 & -2.0 & 0.04 & 0 & 0.0 & - & - \\
\hline Other antibacterial drugs & & & & & & & & & & & & & & & & & \\
\hline Nitrofurantoin (0) & 1,079 & 39.06 & 2.2 & 5.1 & $<0.0001$ & 152 & 14.1 & 1.7 & $1.4-2.0$ & 3245 & 518 & -0.5 & 0.63 & 76 & 7.0 & 1.0 & $0.7-1.3$ \\
\hline Furazidine (0) & 254 & 39.38 & 2.2 & 0.1 & 0.94 & 21 & 8.3 & 0.9 & $0.6-1.5$ & 3240 & 552 & 1.8 & 0.07 & 22 & 8.7 & 2.1 & $1.3-3.5$ \\
\hline Nalidixic acid (0) & 377 & 39.48 & 2.0 & -0.9 & 0.36 & 30 & 8.0 & 0.9 & $0.6-1.3$ & 3284 & 511 & 0.5 & 0.60 & 20 & 5.3 & 1.1 & $0.7-1.8$ \\
\hline Polymixin B (p) & 13 & 39.00 & 2.3 & 0.4 & 0.66 & 2 & 15.4 & 1.5 & $0.3-6.6$ & 2975 & 472 & 1.8 & 0.07 & 1 & 7.7 & 0.9 & $0.1-8.8$ \\
\hline Oxolin acid (0) & 13 & 38.46 & 1.8 & 1.7 & 0.10 & 2 & 15.4 & 1.9 & $0.4-8.7$ & 3270 & 357 & -0.3 & 0.78 & 0 & 0.0 & - & - \\
\hline Antiviral drugs & & & & & & & & & & & & & & & & & \\
\hline Acyclovir (0) & 15 & 39.73 & 1.5 & -0.4 & 0.66 & 0 & 0.0 & - & - & 3229 & 656 & 1.3 & 0.20 & 1 & 6.7 & 2.9 & $0.4-22.5$ \\
\hline Moroxydine (0) & 14 & 39.78 & 1.4 & -0.7 & 0.51 & 1 & 7.1 & 0.9 & $0.1-6.6$ & 3532 & 426 & -2.1 & 0.03 & 0 & 0.0 & - & - \\
\hline Antifungal drugs & & & & & & & & & & & & & & & & & \\
\hline Clotrimazole $(\mathrm{t}+\mathrm{v})$ & 3,077 & 39.52 & 1.9 & -3.6 & 0.0003 & 221 & 7.2 & 0.8 & $0.7-0.9$ & 3307 & 499 & 0.1 & 0.96 & 140 & 4.6 & 0.9 & $0.8-1.2$ \\
\hline Natamycin (v) & 98 & 39.20 & 1.9 & 1.0 & 0.31 & 11 & 11.2 & 1.4 & $0.7-2.6$ & 3347 & 485 & -1.7 & 0.09 & 2 & 2.0 & 0.3 & $0.1-1.2$ \\
\hline Nystatin (0) & 143 & 39.49 & 2.0 & -0.8 & 0.42 & 11 & 7.7 & 0.8 & $0.4-1.5$ & 3288 & 535 & 0.6 & 0.53 & 9 & 6.3 & 1.4 & $0.7-3.0$ \\
\hline
\end{tabular}




\begin{tabular}{|l|c|c|c|c|c|c|c|c|c|c|c|c|c|c|c|c|c|}
\hline Griseofulvin (o) & 24 & 39.79 & 1.2 & -0.9 & 0.38 & 0 & 0.0 & - & - & 3523 & 602 & -1.7 & 0.08 & 0 & 0.0 & - & - \\
\hline Econazole (v) & 129 & 39.53 & 1.5 & -0.6 & 0.55 & 3 & 2.3 & 0.3 & $0.1-0.8$ & 3368 & 546 & -1.4 & 0.18 & 8 & 6.2 & 1.9 & $0.9-4.0$ \\
\hline Povidone-iodine (v) & 43 & 39.86 & 1.9 & -1.4 & 0.18 & 3 & 7.0 & 0.9 & $0.3-2.9$ & 3417 & 540 & -1.7 & 0.09 & 2 & 4.7 & 0.8 & $0.1-3.9$ \\
\hline Miconazole (t) & 22 & 40.14 & 0.9 & -1.5 & 0.14 & 0 & 0.0 & - & - & 3349 & 401 & 0.1 & 0.96 & 0 & 0.0 & - & - \\
\hline Tolnaftate (s) & 13 & 39.15 & 2.0 & 0.4 & 0.71 & 2 & 15.4 & 1.8 & $0.4-8.4$ & 3378 & 401 & 1.1 & 0.27 & 2 & 15.4 & 3.1 & $0.6-17.5$ \\
\hline Ketoconazole (t) & 12 & 39.58 & 0.8 & -0.3 & 0.80 & 0 & 0.0 & - & - & 3360 & 349 & -0.0 & 0.98 & 0 & 0.0 & - & - \\
\hline | \\
\hline Antiparasitic drugs
\end{tabular}

*adjusted for maternal age, parity, employment status and use of other antimicrobial drugs

**adjusted for maternal age, parity, employment status, use of other antimicrobial drugs and gestational age

Route of administration

$0=$ oral

$\mathrm{p}=$ parenteral

$v=$ vaginal

$\mathrm{t}=$ topical

$\mathrm{s}=$ spray

Bold numbers show significant associations

Table 3. The so-called preterm preventive effect of ampicillin and clotrimazole according to the time (trimester) of treatment

\begin{tabular}{|c|c|c|c|c|c|c|c|c|}
\hline \multirow{3}{*}{ Trimester } & \multicolumn{4}{|c|}{ Ampicillin } & \multicolumn{4}{|c|}{ Clotrimazole } \\
\hline & \multirow[b]{2}{*}{$\mathrm{N}$} & \multicolumn{2}{|c|}{ Preterm birth } & \multirow[b]{2}{*}{ POR with $95 \% \mathrm{Cl}$} & \multirow[b]{2}{*}{$\mathrm{N}$} & \multicolumn{2}{|c|}{ Preterm birth } & \multirow[b]{2}{*}{ POR with $95 \% \mathrm{Cl}$} \\
\hline & & No. & $\%$ & & & No. & $\%$ & \\
\hline First & 718 & 45 & 6.3 & $0.70 .5-0.9$ & 766 & 37 & 4.8 & $0.50 .4-0.7$ \\
\hline Second & 1,228 & 98 & 8.0 & $0.90 .7-1.1$ & 1,521 & 113 & 7.4 & $0.80 .7-0.9$ \\
\hline Third & 903 & 66 & 7.3 & $0.80 .6-1.0$ & 1,144 & 93 & 8.1 & $1.90 .7-1.1$ \\
\hline Total & $2,630^{*}$ & $186^{*}$ & 7.1 & $0.80 .7-0.9$ & $3,077^{\star}$ & $221^{*}$ & 7.2 & $0.80 .7-0.9$ \\
\hline
\end{tabular}

*Some pregnant women were treated with ampicillin or clotrimazole by more than one occasion in different trimesters of gestation and these treatments were evaluated separately.

Bold numbers show significant associations

\section{DISCUSSION AND CONCLUSIONS}

As far as we know our study is the first population-based controlled epidemiological study to evaluate the preterm birth preventive effect of 49 antimicrobial drug treatments during pregnancy. Oral ampicillin and vaginal clotrimazole treatment was associated with a reduction of preterm births and with longer mean gestational age at delivery.

The benefits of the HCCSCA are the population-based, large data set which includes 38,151 newborns without birth defects in an ethnically homogeneous (European-Caucasian) population. Major part of underlying maternal diseases and all pregnancy complications were medically recorded. Certain proportions of antimicrobial drug treatments were medically recorded and the time/duration of the treatment was known. The data of confounding factors were available. Birth weight and gestational age were medically recorded, thus the proportion of preterm birth and low birthweight newborns can be evaluated. The distribution of gestational weeks and birth weight groups corresponded well with the Hungarian development standard of birth weight and gestational age (8).
However, this data set has also weaknesses: (i) The causes of maternal infectious diseases, i.e. microbial agents were not recorded in the data set. (ii) The spectrum of antimicrobial drugs corresponded to the time window of the study (between 1980 and 1996) and to the drug market of the Central ("East”) European Hungary (9). (iii) The response rate was $83 \%$, but the prevalence of commonly used antimicrobial drugs and the proportion of preterm births did not show differences in the respondent and non-respondent mothers (7). (iv) The certain part of antimicrobial treatments was based on retrospective maternal self-reported information which was probably prescribed by other physicians, independent of prenatal care or was OTC drugs. The question is whether preterm birth may associate with a similar recall bias as congenital abnormalities (10). However, our data did not indicate an obvious difference in the proportion of medically recorded drugs between the mothers of full term and preterm babies. (v) Nearly all pregnant women with infectious diseases were treated with more than one antimicrobial drug in our study, thus in general it was not possible to evaluate the "pure" effect of drug studied. However, other antimicrobial drug treatments as confounders were considered in the multivariate statistical analysis. (vi) We did not 
differentiate three subgroups of preterm birth: spontaneous labour (about 50\%), preterm premature membrane rupture (30\%) and medically induced preterm birth due to maternal or fetal complications (20\%). (vii) The prevalence of previous preterm births in mothers studied was not known, but about half of pregnant women were primiparae according to the data of the HCCSCA. Of 1,366 and 1,572 firstborn babies born to mothers with ampicillin or clotrimazole treatment, 97 (7.1\%) and 106 (6.7\%) had preterm birth compared with the $9.2 \%$ reference figure in the Hungarian newborn population. Thus, the preterm birth preventive effect of ampicillin and clotrimazole was confirmed in this subgroup as well. (viii) While birth weight is a reliable birth outcome, the gestational age at delivery was based on the last menstrual period which is not reliable. Ultrasound scanning can be used to improve the accuracy of gestational age, but it was rarely performed and/or recorded in our pregnant women during the study period. However, we suppose that this error was the same in the term and preterm births. (ix) Some important confounders, e.g. smoking and alcohol drinking during the study pregnancy were not evaluated in the total data set because our previous studies indicated the unreliability of retrospective maternal self-reported information regarding these risk factors during pregnancy (11). These lifestyle factors were available only in 3,022 mothers of the HCCSCA visited at home and there was no obvious difference in the occurrence of smoking and drinking in mothers with and without antimicrobial drug treatments. (x) Preterm babies have a shorter gestational age, thus it may be associated with a lower frequency of drug use. However, antimicrobial drugs were used rarely in the last month of pregnancy. (xi) The effect of unknown confounding factors (e.g., treated women may be more health conscious) cannot be excluded. However, the above weaknesses existed in all the 49 drugs evaluated but only ampicillin and clotrimazole showed an obvious and consistent preterm birth preventive effect.

A number of studies have shown that abnormal genital flora, either bacterial vaginosis and bacterial vaginosis-related organisms, such as anaerobes and mycoplasmas or vulvovaginitis, is associated with preterm birth (12). Microorganisms from vagina and cervix during pregnancy can gain access to the uterine cavity and infect the placenta, membranes and fetus due to subclinical endometritis $(13,14)$. Women with bacterial vaginosis during pregnancy have at least twice the risk of preterm delivery (15-17). Several randomised controlled trials have indicated the beneficial effect of antimicrobial drugs in the prevention of preterm delivery, particularly when it was caused by premature rupture of the membranes due to concomitant infections $(18,19)$. However, Cochrane Systematic Review (20) and meta-analysis (21) of available data showed conflicting results on the benefits of routine screening and treatment for bacterial vaginosis.

The results of our study are not in agreement with the internationally accepted consensus:

1. Clindamycin is emerging as the antibiotic of choice for the treatment of abnormal vaginal flora and/or bacterial vaginosis and vulvovaginitis in pregnancy (22). We were not able to confirm the preterm preventive effect of clindamycin because it was used only by 7 pregnant women in the data set of the HCCSCA, 1980-1996.

2. The most frequently used drug for the treatment for bacterial vaginosis and vaginitis caused by particularly Trichomonas vaginalis and anaerobes was metrodinazole, sometimes in the combination with miconazole in the data set of the HCCSCA. However, metronidazole did not associate with an obvious preterm preventive effect. Two previous randomised controlled trials using short courses of oral metrodinazole administered late in second trimester did not show reduction in the risk of preterm births as well $(23,24)$.

3. Our study showed, that clotrimazole had a preterm preventive effect in pregnant women with vaginal candidiasis in agreement with our previous findings $(25,26)$ and the results of a prospective randomised controlled trial of Kiss et al. (27). Nevertheless screening for candidiasis is not recommended during pregnancy because moderate to heavy Candida colonisation was not associated with preterm birth in a previous large study (28).

4. Our study indicated the preterm preventive effect of ampicillin as well. Previously ampicillin was used for the prophylaxis in preterm premature ruptures of the membranes (29-31). However, two-thirds of our pregnant women with ampicillin treatment had no genitourinary infections. There are two major groups of microorganism-related mechanism associated with genital infections: ascending genital-tract infection, almost always bacterial and hematogenous spread of maternal systematic infection due to bacterial, viral and parasitic agents. Thus the acute maternal infectious diseases of several pregnant women may also be associated with a higher risk for preterm births and ampicillin may reduce this risk as well.

5. The most beneficial preterm preventive effect of ampicillin and clotrimazole treatment was found in the first trimester of pregnancy. Fetal growth does not begin to occur before 18 completed gestational weeks in normal pregnancies. Thus the preterm birth preventive effect of these drugs is obviously not a direct effect but it may be explained by the eradication of infection. The explanation is that very early preterm birth is more likely to be of infectious etiology than preterm birth just before term (32). Thus the earlier in gestation the abnormal flora of pregnant women is treated, the better is the chance that the intervention may reduce the incidence of preterm birth.

6 . The higher rate of preterm births after oxacillin, metronidazole and sulfamethoxazole+trimethoprin treatment, and the larger proportion of low birthweight newborns after cefalexin and furazidine treatment are also not a direct effect of these drugs, however, they cannot neutralize the preterm or low birthweight inducing effect of microbial agents in the female genital organs.

7. A better balance is needed at the evaluation between risk and benefit of drug treatments during pregnancy. The British National Formulary warns that all drugs should be avoided if possible during the first trimester of pregnancy (33), but about $70 \%$ of pregnant women had drug intake during pregnancy in Hungary (9). Obviously doctors and patients have to consider the benefits and risks of drugs at the indication of their uses in each occasion but particularly during pregnancy. The expected benefit, i.e. the reason of drug use in pregnant women is the treatment of maternal diseases and pregnancy complications. However, the usual risks of drug treatments are extended to the fetal risk including birth defect inducing effect, i.e. teratogenicity of drugs during pregnancy. On the other hand the findings of several studies showed the preterm birth preventive effect of some antimicrobial drugs, and it was confirmed in this study as well. 
An anxiety and fear created by the notion that nearly all drugs cause birth defects have dangerous consequences. (i) Many planned and wanted pregnancies are terminated due to the supposed teratogenic risk of drugs. (ii) The necessary drug treatments are frequently missed, e.g. in pregnant women with infections/ diseases of genital organs. (iii) Pregnant women with necessary drug treatments have a permanent psychological stress. In conclusion, medical doctors and other experts need more education to achieve a better balance at the evaluation of risk and benefit of drug treatments during pregnancy.

Of 136 million total births per year worldwide, more than 4 million newborns die within the first days or weeks of life. The major causes of their death are acute neonatal conditions, mainly preterm birth, birth asphyxia and infections (34). The two major conclusions of our paper are that the HCCSCA is appropriate for the evaluation of births outcomes in general beyond birth defects and a certain part of preterm birth due to infectious diseases particularly caused by genital infections is preventable by the use of appropriate antimicrobial drugs at the right time.

\section{REFERENCES}

1. Czeizel AE, Rockenbauer M, Siffel C, Varga E. Description and mission evaluation of the Hungarian Case-Control Surveillance of Congenital Abnormalities, 1980-1996. Teratology. 2001 May;63(5):176-85.

2. Bjerkedahl T, Czeizel AE, Hosmer DW. Birth weight of single livebirths and weight specific early neonatal mortality in Hungary and Norway. Paediatr Perinat Epidemiol. 1983;3:29-40.

3. Divers MJ, Lilford RJ. Infection and preterm labour: a meta-analysis. Contemp Rev Obstet Gynaecol. 1993;5:71-84.

4. Lettieri L, Vintzileos AM, Rodis JF, Albini SM, Salafia CM. Does "idiopathic" preterm labor resulting in preterm birth exist? Am J Obstet Gynecol. 1993 May;168(5): 1480-5.

5. Czeizel AE. First 25 years of the Hungarian Congenital Abnormality Registry. Teratology. 1997 May;55(5):299-305.

6. czeizel.hu [homepage on the Interenet]. Budapest: AE Czeizel [cited 2007 Jun 19]. List of studies (papers) regarding drug intake during pregnancy based on the Hungarian case-control surveillance of congenital abnormalities. Available from: www.czeizel.hu.

7. Czeizel AE, Petik D, Vargha P. Validation studies of drug exposures in pregnant women. Pharmacoepidemiol Drug Saf. 2003 Jul-Aug;12(5):40916.

8. Joubert K. Standards of the body mass and body length of birth in Hungary on the basis of the 1990-96 nationwide liveborn data. Magyar Nőorvosok Lapja. 2000;63:155-63. (In Hungarian.)

9. Czeizel AE, Rácz J. Evaluation of drug intake during pregnancy in the Hungarian Case-Control Surveillance of Congenital Anomalies. Teratology. 1990;42:402-12.

10. Rockenbauer M, Olsen J, Czeizel AE, Pedersen L, Sorensen HT; EuroMAP Group. Recall bias in a case-control surveillance system on the use of medicine during pregnancy. Epidemiology. 2001 Jul;12(4):461-6.

11. Czeizel AE, Petik D, Puhó E. Smoking and alcohol drinking during pregnancy. The reliability of retrospective maternal self-reported information. Cent Eur J Public Health. 2004 Dec;12(4):179-83.

12. Chin BM, Lamon RF. The microbiology of preterm labor and delivery. Contemp Rev Obstet Gynaecol. 1997;9:285-96.

13. McGregor JA, French JI, Richter R, Franco-Buff A, Johnson A, Hillier S, et al. Antenatal microbiologic and maternal risk factors associated with prematurity. Am J Obstet Gynecol. 1990 Nov;163(5 Pt 1):1465-73.

14. Korn AP, Bolan G, Padian N, Ohm-Smith M, Schachter J, Landers DV. Plasma cell endometritis in women with symptomatic bacterial vaginosis. Obstet Gynecol. 1995 Mar;85(3):387-90.

15. Kurki T, Sivonen A, Renkonen OV, Savia E, Ylikorkala O. Bacterial vaginosis in early pregnancy and pregnancy outcome. Obstet Gynecol. 1992 Aug;80(2):173-7.
16. Hay PE, Lamont RF, Taylor-Robinson D, Morgan DJ, Ison C, Pearson J. Abnormal bacterial colonisation of the genital tract and subsequent preterm delivery and late miscarriage. BMJ. 1994 Jan 29;308(6924):295-8.

17. Hillier SL, Nugent RP, Eschenbach DA, Krohn MA, Gibbs RS, Martin $\mathrm{DH}$, et al. Association between bacterial vaginosis and preterm delivery of a low-birth-weight infant. The Vaginal Infections and Prematurity Study Group. N Engl J Med. 1995 Dec 28;333(26):1737-42.

18. Owen J, Groome LJ, Hauth JC. Randomized trial of prophylactic antibiotic therapy after preterm amnion rupture. Amer J Obstet Gynecol. 1993 Oct;169(4):976-81.

19. Mercer BM, Miodovnik M, Thurnau GR, Goldenberg RL, Das AF, Ramsey RD, et al. Antibiotic therapy for reduction of infant morbidity after preterm premature rupture of the membranes. A randomized controlled trial. National Institute of Child Health and Human Development Maternal-Fetal Medicine Units Network. JAMA. 1997 Sep 24;278(12):98995.

20. Brocklehurst P, Hannah M, McDonald H. Interventions for treating bacterial vaginosis in pregnancy. Cochrane Database Syst Rev. 2000;(2):CD000262. Update in: Cochrane Database Syst Rev. 2003;(2): CD000262.

21. Leitich H, Brunbauer M, Bodner-Adler B, Kaider A, Egarter C, Husslein P. Antibiotic treatment of bacterial vaginosis in pregnancy: a meta-analysis. Am J Obstet Gynecol. 2003 Mar;188(3):752-8.

22. Ugwumadu A. Role of antibiotic therapy for bacterial vaginosis and intermediate flora in pregnancy. Best Pract Res Clin Obstet Gyneacol. 2007 Jun;21(3):391-402.

23. Carey JC, Klebanoff MA, Hauth JC, Hillier SL, Thom EA, Ernest JM, et al. Metronidazole to prevent preterm delivery in pregnant women with asymptomatic bacterial vaginosis. National Institute of Child Health and Human Development Network of Maternal-Fetal Medicine Units. N Eng J Med. 2000 Feb 24;342(8):534-40.

24. McDonald HM, O’Loughlin JA, Vigneswaran R, Jolley PT, Harvey JA, Bof A, et al. Impact of metronidazole therapy on preterm birth in women with bacterial vaginosis flora (Gardnerella vaginalis): a randomized, placebo controlled trial. Br J Obstet Gyneacol. 1997 Dec;104(12):1391-7.

25. Czeizel AE, Rockenbauer M. A lower rate of preterm birth after clotrimazole therapy during pregnancy. Paediatr Perinat Epidemiol. 1999 Jan;13(1):58-64.

26. Czeizel AE, Fladung B, Vargha P. Preterm birth reduction after clotrimazole treatment during pregnancy. Eur J Obstet Gynecol Reprod Biol. 2004 Oct 15;116(2):157-63.

27. Kiss H, Petricevic L, Husslein P. Prospective randomised controlled trial of an infection screening programme to reduce the rate of preterm delivery. BMJ. 2004 Aug 14;329(7462):371.

28. Cotch MF, Hillier SL, Gibbs RS, Eschenbach DA. Epidemiology and outcomes associated with moderate to heavy Candida colonization during pregnancy. Vaginal Infections and Prematurity Study Group. Am J Obstet Gynecol. 1998 Feb;178(2):374-80.

29. Boyer KM, Gotoff SP. Prevention of early-onset neonatal group B streptococcal disease with selective intrapartum chemoprophylaxis. N Engl J Med. 1986 Jun 26;314(26):1665-9.

30. Amon E, Lewis SV, Sibai BM, Villar MA, Arheart KL. Ampicillin prophylaxis in preterm premature rupture of the membranes: a prospective randomized study. Am J Obstet Gynecol. 1988 Sep;159(3):539-43.

31. Morales WJ, Angel JL, O’Brien WF, Knuppel RA. Use of ampicillin and corticosteroids in premature rupture of the membranes: a randomized study. Obstet Gynecol. 1989 May;73(5 Pt 1):721-6.

32. Lamont RF. Can antibiotics prevent preterm birth -- the pro and con debate. BJOG. 2005 Mar;112 Suppl 1:67-73.

33. Vallance P. Drugs and the fetus. BMJ. 1996 Apr 27;312(7038):1053-4.

34. World Health Organization [homepage on the Interenet]. Geneva: WHO [cited 2007 Jun 19]. The World health report 2005: make every mother and child count. Available from: http://www.who.int/whr/2005/ whr2005_en.pdf. 